\title{
Professor Dr. Manoel Gonçalves Ferreira Filho. Catedrático de Direito Constitucional.
}

Sucedendo o Prof. Dr. Cândido Motta Filho, é o Prof. Dr. Manoel Gonçalves Ferreira Filho novo titular da cátedra de Direito Constitucional.

Filho do Sr. Manoel Gonçalves Ferreira e de D. Elsy Moraes Ferreira, nasceu nesta capital aos 21 de junho de 1934. Casou-se em 1958 com a Dra. Yvete Senise Ferreira.

Fêz os estudos primários no externato "Assim Pacheco" e os secundários no "Colégio São Luís" desta capital.

Em 1953 ingressa na Faculdade de Direito da Universidade de São Paulo, colando grau de bacharel em Ciências Jurídicas e Sociais em 1957, após brilhante currículo.

Fazendo o curso de doutoramento na Universidade de Paris, recebe o título de doutor em maio de 1960, com a menção "très bien".

Embora muito jovem, S. Ex. ${ }^{\text {a }}$ conta com excepcional experiência docente; desde 1965, é livre-docente de Direito Constitucional e lecionou essa matéria, como regente, nesta Faculdade e na Faculdade Paulista de Direito da Pontifícia Universidade Católica; regeu, também, nesta Faculdade, a cátedra de Direito Internacional Privado e, na Universidade Católica, a cátedra de Introdução à Ciência do Direito da qual é professor assistente.

Na Faculdade de Filosofia Ciência e Letras de São Bento, da Pontifícia Universidade, onde coordenou o curso de Ciências Sociais, e na de Ciências e Letras da Universi- 
dade Católica de Campinas, regeu as cátedras de História das Idéias Políticas e Política, respectivamente.

É ainda sócio do Instituto dos Advogados, Conselheiro da Associação dos Advogados de São Paulo e integrou a Comissão encarregada de estudar a adaptação da Constituição do Estado à nova Constituição do Brasil.

Pesquisador do Direito, publicou vários trabalhos doutrinários, pareceres e conferências constituindo a bibliografia a seguir.

Bibliografia.

Artigos doutrinários.

1. Le Statut Constitutionnel des Partis Politiques au Brésil, en Italie, en Allemagne et en France, (Tese de doutoramento aprovada na Faculdade de Direito da Universidade de Paris, em 1960.)

2. Aspectos Políticos do Confronto Parlamentarismo $v$. Presidencialismo, na revista "Sociologia", vol. 24, n. 3, 1962.

3. O Estado de Sítio, tese apresentada no concurso à livre-docência de Direito Constitucional, na Faculdade de Direito da uSP em 1964.

4. Democracia, Organização Política e Regime de Govêrno, na "Revista da Pontifícia Universidade Católica de São Paulo", julho-dezembro de 1964.

5. Os Partidos Políticos nas Constituições Democráticas, Belo Horizonte, 1966.

6. A Extensão do Poder Regulamentar na Constituição Francesa de 1958, in "Justitia", vol. 51, 1965 e na "Revista de Direito Administrativo", vol. 84, 1966, S. Paulo.

7. Curso de Direito Constitucional, edição Saraiva, São Paulo, 1967. 
8. Problemas Politicos do Sub-desenvolvimento na "Revista da Universidade Católica de São Paulo", julhodezembro, 1967.

9. Notas sôbre a Sistemática do Ato Complementar, na "Revista de Direito Público", 1969.

10. Paz, Tensões e Desenvolvimento, na "Revista Convivium", São Paulo, 1968.

Pareceres.

11. A Constitucionalidade da Lei 5.516 do Estado do Paraná, ao Dr. Luís Carlos Mello Motta, em 10 de março de 1967.

12. A Constitucionalidade de aumento do Impôsto de Circulação de Mercadorias, à Secretaria da Fazenda do Estado de São Paulo, em 25 de abril de 1968.

13. A Revogação do art. 20 da Constituição do Estado, à Secretaria da Fazenda do Estado de São Paulo, em 27 de agôsto de 1968.

Conferências.

14. Democracia e Desenvolvimento Econômico, aula inaugural dos cursos da Universidade Católica de Campinas, em março de 1963, publicada na "Revista da Universidade Católica de Campinas".

15. Parlamentarismo, Presidencialismo, Sistemas Eleitorais e Estruturas Partidárias, conferência proferida na Faculdade de Direito da usP, em ciclo de estudos do Instituto dos Advogados de São Paulo e do Instituto de Direito Público.

16. O Poder Democrático e a Escolha entre Parlamentarismo e Presidencialismo, conferência proferida na Faculdade de São Bento, sob o patrocínio do Centro de Ciências Sociais. 


\section{A solenidade de Posse.}

Com a tese Do Processo Legislativo, o Prof. Ferreira Filho concorreu à cátedra de Direito Constitucional desta Faculdade. Classificado em primeiro lugar, entre outros notáveis candidatos, é nomeado em 25 de setembro de 1969 e toma posse da cátedra a 13 de outubro do mesmo ano, em sessão solene da Congregação, presidida pelo $\mathrm{Sr}$. Diretor, Prof. Dr. José Pinto Antunes.

Introduzido no salão nobre, pelos Professôres Cândido Motta Filho, Ataliba Nogueira e Philomeno Joaquim da Costa, recebe a saudação do Prof. Washington de Barros Monteiro, que em seu discurso enaltece a personalidade do jovem mestre e augura-lhe senda "maravilhosa", "iluminada de claridade".

\section{Discurso de saudação do prof.}

Washington de Barros Monteiro.

Reune-se a Congregação da Faculdade de Direlto para receber festivamente seu nôvo professor de Direito Constitucional, o dr. Manoel Gonçalves Ferreira Filho.

O implemento da idade legal havia determinado o afastamento do antigo catedrático, Professor Cândido Mota Filho. Abriu-se assim caminho para preenchimento do cargo vago.

Sentiam todos a grande importância da escolha do sucessor, principalmente nesta época em que, por todos os lados, se instaura o "vazio político" e a nação se sente ameaçada por um perigo latente e constante.

O Direito Constitucional sempre foi estudado nesta Casa com especial carinho. Muito mais do que um simples ramo, mais ou menos frondoso, o Direito Constitucional é o verdadeiro tronco, de que brotam e ganham vida todos os demais ramos do direito. 


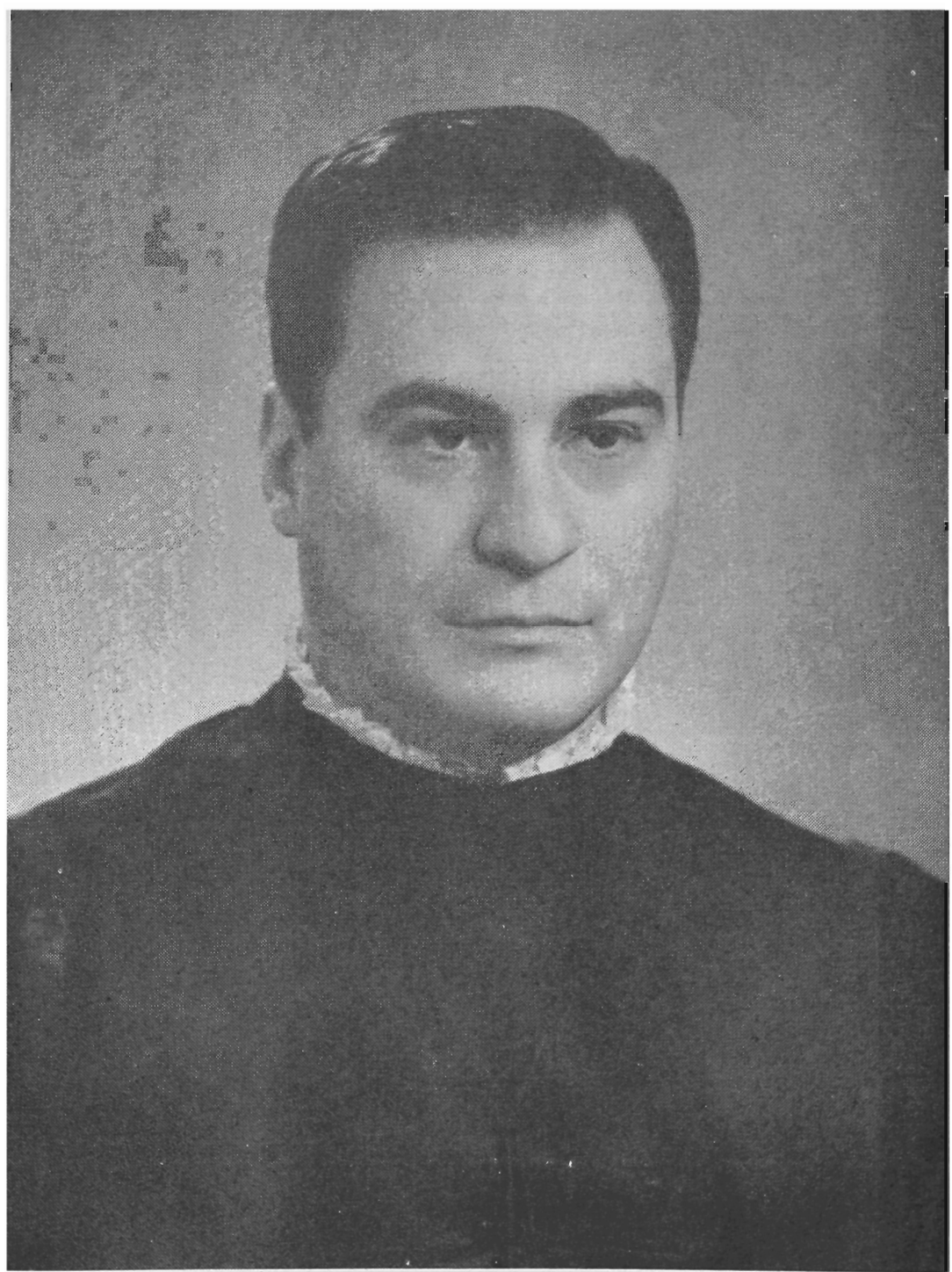

Prof. Dr. Manoel Gonçalves Ferreira Filho, Catedrático de Direito Constitucional. 
Berço de grandes constitucionalistas, no passado e no presente, de esperar seria que o concurso a abrir-se converter-se-ia na oportunidade para que um eminente mestre sucedesse ao professor que se aposentava e que, por sua vez, havia sucedido a Sampaio Dória e êste a Herculano de Freitas.

Efetivamente, o concurso não desapostou. Muito ao revés, na seqüência dos acontecimentos que o envolveram, veio a transformar-se em magnífica demonstração de saber e de cultura.

Foi um torneiro memorável, que marcará época na vida jurídica e universitária, em que engrandecidos e dignificados, cada vez mais respeitados, saíram os que nêle tomaram parte.

Difìcilmente, um nôvo concurso logrará congregar, em qualidade e quantidade, igual pugilo de competidores, tão equilibrados e tão valorosos, que souberam imprimir às provas, a que se submeteram, no mais alto grau, a projeção de sua cultura e de sua ilustração.

José Afonso da Silva concorreu com tese referente à aplicação das normas constitucionais. Intrìnsecamente, trabalho perfeito. Soube o candidato confirmar que, realmente, é um "autêntico jurista, um cultor sério e erudito da ciência do direito, um jurista de qualidades ímpares que sabe e conhece os assuntos que aborda".

José Luís de Anhaia Melo escreveu sôbre separação de podêres à guarda da constituição. Com o talento e o brilho de sua inteligência, amadurecida em longos anos de estudos, evidenciou que conhece e domina todos os escaninhos constitucionais, porque a Constituição, como ensina Hermes Lima, é ponto de referência, é ponto de valor, é ponto de estabilidade, é ponto de fixação de competências, qualquer que seja o regime, sendo certo ainda, como antecipara Rui, que "os povos não amam suas constituições senão pela segurança das liberdades que elas lhes prometem". 
José Loureiro Júnior, autor de magnífico trabalho sôbre delegação legislativa, trouxe a debate um tema atual, polêmico, repleto de dificuldades, defendendo, com maestria e proficiência, seus pontos de vista.

Por fim, Manoel Gonçalves Ferreira Filho ofereceu sua preciosa contribuição acêrca do processo legislativo e não devo ocultar a profunda impressão que me causou o jovem professor, o qual, inteiramente devotado ao que tinha de fazer, se mostrou exímio em tôdas as provas.

Nessa árdua jornada, sempre povoada de temôres e que é o concurso, revelou êle um extraordinário sentimento de convicção e de fôrça. Como Rivière, o personagem de Saint-Exupery, em seu livro Vôo Noturno, uma vez que traçou o caminho, já não mais poderia deixar de o seguir. Sempre para a frente, soube grangear a admiração de seus examinadores, bem como o respeito de seus antagonistas.

Parafraseando Virgílio posso agora dizer: quorum pars parva fui. Inesperadamente convocado a integrar a respectiva comissão examinadora, superiormente presidida pelo Professor Ataliba Nogueira, e composta dos ilustres Professôres Pedro Calmon, Lourival Vilanova e Raul Machado Horta, tive, de imediato, sensação das graves dificuldades, com que os examinadores se veriam a braços.

Juiz que fui, durante quase tôda a minha vida, talvez haja sofrido, mais do que os outros, as angústias da perplexidade, o receio de não ser justo, o mêdo de errar, porquanto como disse Jacó Wasserman, "a justiça é como a vida e a injustiça é como a morte".

Enfim, vencidas as hesitações, decidiram-se todos por Manoel Gonçalves Ferreira Filho. Recordo-me com alívio e também com alegria da espontânea reação da assistência, - que atentamente acompanhava o julgamento, e que, ruidosamente, saudou o classificado em primeiro lugar.

Naquele momento, lembrei-me da frase de Teodoro Dreiser (Sister Carrie): "abençoados os filhos do esfôrço, 
porque tentam e nutrem esperanças. E abençoados, também, os que, sabendo disso, sorriem e aplaudem".

Sem dúvida, qualquer dos candidatos estaria em condições de ocupar a cátedra. Pelas suas próprias virtudes, morais e intelectuais, pela sua integridade - a obrigação mais absoluta do indivíduo para consigo mesmo - qualquer dêles dignificaria a cátedra e saberia corresponder às tradições desta Casa, balisadas pela cultura e pelo saber.

Ai da Comissão Julgadora, porém! Um só dêles poderia ter a primazia e coube ela a Manoel Gonçalves Ferreira Filho, que, efetivamente, prestou um dos mais belos concursos, que tive a ventura de acompanhar nesta Faculdade, primeiro como estudante e depois como professor.

Sua dissertação foi fruto de ingentes trabalhos e estensas cogitações, em que a clareza da exposição bem revelava o espírito ordenado e firme de seu autor.

Depois, soube defendê-la com extraordinária lucidez, pondo à prova uma dialética segura e vigorosa. De um extremo a outro da discussão, o candidato mostrou sempre a mesma exatidão, a mesma competência e a mesma profundidade.

A prova didática foi excepcional. Muito bem montada, sua preleção foi um modêlo de bom-gôsto e de ordenação, até de dicção.

Prova escrita límpida, plana, fluente, isenta de qualquer eiva, em que se vislumbrava a formação francesa, retraçada por Rivarol: ce qui n'est pas clair, n'est pas français.

No conjunto das provas, o Professor Manoel Gonçalves Ferreira Filho exibiu, com a maior exuberância, as qualidades precípuas da mais perfeita manifestação do pensamento.

Puderam assim os julgadores caminhar certo, firme, para o ponto exato, indo direito ao centro irradiado, que deixava, clara e patente, a fonte da verdade, que, inicial- 
mente, nos fizera estremecer, gerando a perplexidade e a dúvida.

Todos os examinadores puderam proclamar então, sem sombra de vacilação, sem êrro possível, com tranqüilidade absoluta, quem havia merecido, com justiça, o primeiro lugar.

E agora, nesta solenidade, que coroa o concurso, posso comentar: feliz a Faculdade que, em tal competição, conclama quatro candidatos, superiormente dotados de tantas qualificações; feliz a Faculdade que pode conferir a suprema láurea universitária, sem que sua decisão desperte qualquer contestação; feliz esta Faculdade, que passará a contar com um professor como Manoel Gonçalves Ferreira Filho, animado sempre do mais alto senso do dever e que, em todos os lances de sua existência, tem imprimido a mais aguda exação no cumprimento de suas obrigações.

Como é difícil, sobretudo neste instante, a missão do professor. Na sala das becas, afirmou Eça, êle troca a graça mundana pela sensaboria catedrática, o sujeito deixa de ser um homem para ser um lente, onde faz voto de melancolia e de perpétua carranca, onde se substitui a alma por um compêndio.

Por certo, Professor Manoel Gonçalves Ferreira Filho, não será essa sua posição. Devido à juventude, aos predicados que formam sua personalidade, sua facilidade de comunicação, estará em condições de bem exercer profícua influência sôbre a mocidade acadêmica, e, portanto, sôbre a felicidade da própria pátria.

Estudioso, diligente, cuidadoso, poderá, no desempenho de sua missão educativa, vir a ser um elo vivo entre as gerações. Como proclamou outro eminente professor desta Faculdade, Herculano de Freitas, não se ensina sòmente para analisar textos ou para explicar matéria técnica, mas, também, e muito, para gerar e despertar idéias e sentimentos. 
Tem-se dito dos políticos de nossa terra que criaram o vácuo em tôrno das instituições políticas. Que se não diga o mesmo dos nossos professôres. $\mathrm{E}$ isso jamais se dirá de Manoel Gonçalves Ferreira Filho. Estamos certos de que sua senda, nesta Casa, em prol da juventude e da grandeza da pátria, será maravilhosa, iluminada de claridade.

Estamos certos de que triunfará, pois, posso dizer, modificando uma fórmula célebre, que, para executar uma tarefa, preciso é um motivo para perseverar; e para vencer, preciso é ter a esperança plausível do sucesso.

Meu caro Professor: Seja benvindo.

\section{Oração do prof. Manoel Gonçalves Ferreira Filho.}

Agradecendo a saudação recebida, o nôvo catedrático pronuncia o seguinte discurso:

“Ao vir para esta tribuna - devo confessá-lo - bem quisera que as musas me socorressem, dando-me, como ao Poeta, "um som alto e sublimado, um estilo grandíloco e corrente."

Não o desejava por mim, mas por vós. Não o pedia, para brilhar, com eloqüência de empréstimo, mas para não desmerecer, com palavras medíocres e cansadas, meus Mestres, minha Casa e particularmente o jurista que me saudou.

Quisera eu contar, ainda que por um breve momento, com o verbo rebrilhante de qualquer dos oradores que foram a glória da Academia, para, à altura, responder ao eminente Prof. Washington de Barros Monteiro. Só assim minhas palavras não pareceriam mesquinhas, diante do verbo generoso que viu em mim tantos méritos, tantos méritos que, só tendo-os todos, pudera realmente ser digno da Congregação que me recebe. Não os tenho, por isso, o 
elogio que, do fundo d'alma, agradeço, acima de tudo exalta a bondade do grande professor que há pouco falou.

Só aos poetas, porém, é que as musas socorrem. Por isso, é, sem a inspiração que a solenidade exigiria, sem a palavra rutilante a que se habituou esta Academia, que me dirijo a vós, mestres da Congregação. Que a sinceridade, porém, de que é rica a minha palavra, supra a pobreza da invenção.

Dando o primeiro passo entre os professôres do Largo de São Francisco, tenho de recordar os que primeiro guiaram meus passos, na vida, no estudo e no Direito. Na vida, meus pais, a quem devo a graça de haver podido, sem partilha, dedicar-me ao estudo, de quem recebi, sempre, estímulo para ir mais à frente e mais adiante.

No estudo e no Direito, aos professôres, cujo ensinamento formou meu espírito, moldou meu senso jurídico. Não poderia eu, particularmente, passar em silêncio, neste instante para mim singular, a dívida que tenho para os Mestres ilustres, a quem devo o que sei e que, benevolentes, acolhem, em seu meio, um discípulo ainda deslumbrado. É êsse o caso do eminente Prof. Cândido Motta Filho a quem tenho a honra de suceder, Ministro do Supremo, Ministro de Estado, insigne jurisconsulto, literato que alcançou a Academia Brasileira de Letras.

Minhas senhoras e meus senhores.

Nesta Casa é que me apaixonei pelo Direito, nêle é que hauri as lições indeléveis que estruturam o meu saber.

Foi nesta Casa que um Mestre, de alma generosa, gravou em mim, para sempre, que o Direito nasce do coração dos homens, que o Direito não é o fruto amargo da vontade do mais forte, mas provém da natureza humana, em tôda parte, em todos os tempos, igual a si mesma e resplandescente da imagem e da semelhança de Deus.

Foi de outro Professor, amigo de lições risonhas, que aprendi a segunda lição. Foi êle quem me ensinou não 
servir o homem ao Estado, mas o Estado ao homem, porque é aquêle um meio e não um fim.

Foi, nos bancos acadêmicos, de outro Mestre eminente que ganhei a experiência da pesquisa, da consulta às fontes e com isso o convívio sem par dos grandes juristas. Em suas aulas, todos os dias cuidadosamente preparadas, o ensinamento não era ditado da cátedra e ex cathedra. Era construído num diálogo, em que, diante de nossos olhos, os mais sábios jurisconsultos traziam a debate suas opiniões. Com isso, nós todos, os alunos, vía-mo-nos admitidos nos mais altos círculos da Ciência Jurídica, admitidos ao convívio dos Chiovenda, Betti, Carnelutti, e tantos outros. Por isso, todos nós nos sentíamos um pouco jurista, quando, estimulados pelo Mestre, trazíamos a público, em aula, trabalhos nossos, de pesquisa e esfôrço pessoal, ainda que feitos para a preparação dos exames, ainda que de pobre valor.

Não é só, todavia, por essa lição que tal jurista é merecedor de minha gratidão. Da minha como da de muitos outros que, nos últimos anos, ascenderam ao magistério universitário. Ninguém mais do que êle estimulou os jovens a ingressar na carreira docente, ninguém mais do que êle batalhou para que a Douta Congregação tolerasse, nos moços estudiosos, imperfeições no saber, certo de que, amadurecendo na convivência diuturna dos grandes Mestres, dentro em pouco êsses moços seriam dignos dela.

Esse apôio aos jovens, porém, não proveio de um Professor isolado. Não faltou êsse mesmo espírito aos que o sucederam na direção desta Escola, sempre apegados ao desenvolvimento da Ciência jurídica e à formação de novos juristas que, não desmerecendo o passado venerando desta Casa, mantenham no futuro o seu glorioso presente.

Por todo êsse amparo, sou, como devera, profundamente reconhecido.

Egrégia Congregação, pela porta honesta do Concurso, perante a vigilância indormida dos Mestres que a honram, 
pelo julgamento de uma Banca de homens probos e jurisconsultos de escol, é que sou admitido no rol dos catedráticos da Academia: Entro - ouso dizê-lo - de cabeça erguida, como de cabeça erguida sou recebido. Mas não venho sòzinho, Douta Congregação.

Não venho só, porque não chegaria aqui se tôda uma plêiade de amigos não me aparasse em cada instante da caminhada. Quem me trouxe até vós, Egrégia Congregação, não foi o esfôrço pessoal de um lutador solitário, quem me impeliu até aqui foram lado a lado dois gigantes: o Amor e a Amizade. Foi um amor que encontrei, com o Direito, nos bancos desta Escola, foi a amizade de um pugilo sem igual de moços e moças de minha geração, foi a amizade de alunas e alunos, de ex-alunos e de ex-alunas, foram êsse Amor e essa Amizade que me ergueram até aqui.

Quem já fêz um Concurso não desconhece como é tempestuoso, para a alma do candidato, o seu desenrolar. Mil nuvens, mil especulações, mil preocupações ameaçam a concentração do estudioso, semeiam de dúvidas e temores a sua mente. Tudo isso, porém, o Amor não permitiu que chegasse até mim, isolando-me com uma sebe de carinho, absorvendo todos os golpes e embates, para que eu não os sofresse, para que eu não os acusasse.

Mil desfalecimentos, mil tentações, durante as provas, solapam a confiança, abalam a tenacidade daquêle que deve lutar, sem desânimo, até a decisão final. Como poderia eu, todavia, desanimar se, a cada instante, recebia o apôio e o estímulo de amigos que tudo largaram, estudos, negócios, ocupações, para, a cada momento, me revigorarem com o calor de seu aplauso.

A vitória trouxe-me a cátedra, sonho de três lustros, mas se êsse prêmio não me houvesse chegado, de muito estaria eu exultante só por haver sentido que amigos eu tenho. Tanto quanto da Cátedra disso me orgulho. Por isso, muitíssimo fiquei, como estou, comovido. Quem teve 
por si amigos que criam no amigo mais que êste em si próprio, que jamais duvidaram do que parecia inalcançável, que superaram divergências ideológicas, para amparálo com tôdas as fôrças, tem de exultar. Por isso, do fundo do coração tenho de agradecer tudo o que devo àquêles que a si mesmos se chamavam de "a torcida".

Não venho só, Douta Congregação, porque comigo vêm êsses amigos de vinte anos e êsses amigos de há vinte anos. Vêm comigo para um trabalho comum, em prol da renovação do ensino do Direito, em prol da renovação da Democracia.

Chegamos no bom momento. Já a Faculdade revela, mesmo a quem só enxergar o aspecto externo, a chegada de nova primavera. À medida que suas instalações se renovam, surgindo por um esfôrço sem par as condições de um trabalho profícuo, a renovação do ensino jurídico se prepara.

Não venho propô-la, venho servi-la. A urgência de uma renovação do ensino jurídico, da adoção de processos didáticos mais consentâneos com os tempos que vivemos, já foi percebida, há tempos, pelos Mestres desta Casa. E, pelo esfôrço de muitos, ela já começou, mesmo antes que, para tanto, as condições materiais aparecessem. Minha consciência, entretanto, não teria paz, se eu, neste primeiro pronunciamento, nâo me alistasse entre os que trabalham por essa reforma, se eu não insistisse em dever ela fazer-se o mais rápido possível.

Essa renovação - há de ser feita no método e na estrutura curricular. Essas duas linhas terão de ser exploradas, se se quiser revigorar o ensino do Direito, hoje abastardado pela multiplicação de pseudo-faculdades onde o diploma depende de bem pouco - hoje anquilosado por uma rotina secular.

A renovação metodológica é imprescindível. É preciso dar menor realce ao método puramente expositivo, à preleção "ex cathedra", no ensino do Direito. Já não goza êsse 
método, - é certo - como até bem pouco, de exclusividade no ensino jurídico. De fato, em tempos que não se passaram há tanto, tôdas as aulas eram conferências, e nem sempre conferências originais...

Entretanto, a palestra continua a ter primazia nas Faculdades de Direito. Sem dúvida, a palavra fácil e eloqüente de Mestres, que são oradores, traz enlêvo e prazer para o estudante. Deixa-o passivo, todavia, e nisso está o seu primeiro, e grave defeito. O aluno, habituado a êsse método, vem para a aula como iria a uma sessão literária, um pouco por prazer estético, um pouco por obrigação, mas sempre para algo onde o seu papel é de mero espectador. Ouve a lição, sem dúvida goza de bons momentos, se a palavra do Mestre fôr culta e brilhante, e volta-se para outros interêsses, guardando quase nada do que escutou.

Tal situação é condenada por tôda a didática moderna. Esta insiste no caráter ativo que deve ter o aprendizado, para que dê bons frutos. Sublinha a necessidade de impor ao aluno participação na aula, tirando-o de uma atitude, fria e crítica, de mero espectador, às vêzes compulsório.

Por outro lado, o método meramente expositivo se revela inadequado para a principal missão atribuída a uma Faculdade de Direito, na época atual. Serve êle para descrever uma realidade, para desenhar um quadro do que é a Lei, o conjunto de normas vigentes, ou o Justo, o conjunto de princípios que devem inspirar essas regras. Não convém para ensinar o estudante a raciocinar de modo jurídico.

Ora, quando as leis se sucedem em turbilhão, quando o direito positivo muda a cada instante e não dura mais que a rosa, mais que "l'espace d'un matin", o principal cuidado do Professor de Ciências jurídicas não haverá de ser a descrição pormenorizada do Direito vigente, o comentário e a exegese minuciosa de cada uma de suas regras. Isso de pouco adiantaria, pois mesmo o aluno que tudo 
isso aprendesse, proveito exígüo retiraria. De fato, em virtude dessa instabilidade, quando tivesse de caminhar por si na vida profissional, o que teria aprendido estaria sepultado no cemitério das leis revogadas.

É mais importante ensinar o aluno a raciocinar. É preciso acostumá-lo a pensar por si, guiando-o sim, mas sem deixá-lo passivo, à espera do bocado feito. Tem, por isso, o Professor de habituar o estudante a enfrentar problemas, a pesquisar soluções. $E$ isso só é possivel se se exigir dos acadêmicos participação ativa no curso jurídico.

Essa renovação metodológica há de ser completada pela flexibilidade curricular. Sem dúvida, uma base sólida, com os principios fundamentais de todo o Direito, deve ser dada a todos os alunos. Todavia, é sempre verd́adeira a lição do filósofo: "Mais vale uma cabeça bem feita do que uma cabeça bem cheia." Dessa verdade esquecem-se os que pretendem fazer de todo acadêmico de Direito um erudito, capaz de versar com a mesma segurança qualquer dos ramos do Direito. Lamentàvelmente o resultado freqüente é o bacharel, tendo dispensado sua atenção, saber de tudo quase nada.

É de se convir que estamos numa época de especialização. Esta é fruto da divisão do trabalho, princípio que permitiu o desenvolvimento acelerado nos dois últimos séculos. Pode-se ter a nostalgia dos homens de saber universal, saudades dos juristas que sabiam tudo. Na formação profissional do bacharel, hic et nunc, entretanto, não é crivel que se descuide de lhe permitir um certo grau de especialização, segundo suas inclinações e planos futuros.

Apenas, com essa renovação do ensino jurídico, emérita Congregação, é que será possível restaurar o prestígio hoje amesquinhado do bacharel. Só assim os jovens bacharéis poderão, sem humilhações e percalços, exercer a profissão que escolheram, logo que saidos dos bancos acadêmicos.

A renovação do ensino jurídico é meta que faz vibrar em mim o professor. Mas sou professor de Direito Consti- 
tucional e da Faculdade do Largo de São Francisco, sob cujas arcadas o apêgo à Liberdade e à Democracia sempre vicejaram. Não me posso furtar, por isso, de postular também a renovação da Democracia no Brasil.

Nossa história revela um paradoxo: o constante apêgo aos ieais democráticos, o constante esboroar das instituições democráticas. Raros povos, em condições como a do nosso, assinala Jacques Lambert, demonstram tanto apêgo à Democracia. Apesar disso, com tôda a facilidade, em face de crises nem sempre graves, sossobram as constituições democráticas. E esfacelam-se, enquanto o povo contempla inerme, como se não lhe afetasse a destruição dessas instituições.

Poucos são os que se perguntam por que tal se dá, raros cuidam de pensar, em vez de lamentar ou maldizer, em vez de buscar explicações obscuras que exoneram a responsabilidade das elites. Invocam-se fôrças ocultas, amaldiçoam-se os desígnios tortuosos de potências estran. geiras. Sugerem-se culpas: a ambição, a fraqueza, a corrupção, a tibieza, a loucura, mas ninguém cuida de procurar, com espírito científico, as causas do que ocorre.

É essa a missão da Universidade, é essa uma tarefa a que a Cadeira de Direito Constitucional tem de dedicar-se.

Sabe-se que a Democracia pressupõe certas condições, para que deite raizes. Ela, como observa Duverger, um regime para "povos maiores". Exige um mínimo de desenvolvimento cultural, um certo grau de adiantamento econômico e de amadurecimento social, a fim de que possa prosperar. Tudo isso se sabe, mas entre os que o sabem pouquíssimos são os que se lembram de perguntar, e muito menos de investigar, até que ponto essas condições se realizam entre nós, de procurar a tão mencionada, e tão desconhecida, realidade brasileira.

Ora, é a partir dessa realidade que as instituições se vão estruturar. Estas, por perfeitas que sejam nos textos, 
in abstracto, não poderão dar os frutos almejados, se lhes faltarem as condições necessárias. Por isso, não basta estabelecer instituições democráticas para criar Democracia. Não é suficiente copiar as constituições estrangeiras para obter, sob outro sol, a Democracia!

Essas instituições que, sem embargo do apêgo à Democracia, desabam a um sôpro, sem lágrimas e sem sangue, são, muita vez, o tronco sem vida do que foi enxertado, ao sabor da moda, sem se cogitar da adequação do solo. Não merecem o pranto, não há por que julgar que sua morte é a extinção da Democracia.

Não se estabelece a Democracia num país só porque nele se adota o sufrágio universal à francesa, o parlamentarismo à inglêsa ou o federalismo à americana. Essa é uma ingenuidade dos liberais, mas dos liberais que se esqueceram da lịcão de Montesquieu. De fato, que é o Espírito das Leis senão o estudo de como o contexto social influência e inspira as leis? De como as instituições dependem do meio sôbre o qual se erguem?

Só estará definitivamente instalada a Democracia no Brasil quando ela fôr institucionalizada segundo nossas condições, quando fôr encontrada a versão brasileira da Democracia, como o parlamentarismo é a britânica e o presidencialismo é a estadunidense. Realmente, o estabelecimento da Democracia não é a adoção de um arcabouço de desenho uniforme, apto a ser utilizado em qualquer ponto do globo, em qualquer instante da história. Ao contrário, para que verdadeiramente cada povo se possa governar, é preciso estruturá-la de forma diferente, segundo as circunstâncias, as condições e o momento. Não há receita universal de Democracia!

Instituições que conferem a um povo rico e desenvolvido a Democracia, não são as que estabelecem a Democracia num país em desenvolvimento. Com efeito, o desenvolvimento econômico pode perturbar e destruir instituições, 
democráticas, assim como estas podem sacrificar o desenvolvimento. A experiência recente nô-lo revela no próprio Brasil.

O desenvolvimento gera e excita tensões. Pressupõe a arrancada para o desenvolvimento, alto grau de investimentos. Estes, se a prazo mais ou menos longo é que produzem frutos, desde logo criam reivindicações, acalentam pretensões. Ora, quanto mais sensíveis são as instituições à opinião pública, mais tenderão elas a satisfazer as solicitações de maior parte no produto, com sacrifício no investimento. A Democracia age assim contra o desenvolvimento, e pode matá-lo. Por outro lado, se as instituições resistem a essas pretensões, o descontentamento instiga à desordem, preparando o caos e sua inexorável conseqüência, o advento da autocracia. A Democracia, pois, ameaça o desenvolvimento e o desenvolvimento a Democracia. Conciliá-los eis o problema magno da política brasileira.

Querer a Democracia para o Brasil, portanto, não é pregar êste ou aquêle modêlo, é antes de mais nada a busca de novos caminhos. É uma tarefa de desbravamento, é uma tarefa para bandeirantes e, como tal, para a Universidade de São Paulo.

Não será talvez épica a pesquisa, faltar-lhe-á o romantismo da procura das esmeraldas. É, porém, a batalha de nosso tempo. Cumpre, a tôda pressa, estudar o problema da institucionalização da Democracia no Brasil, tendo em vista nossas condições, particularmente a desigualdade entre os dois Brasis, tendo em vista, sobretudo, a tensão gerada pelo desenvolvimento econômico. É essa uma tarefa para a Universidade, para a Faculdade, para a cadeira de Direito Constitucional. $\dot{E}$ isso que o momento reclama de nós. E se não atendermos a êsse imperativo, ilustre Congregação, a cada tragédia política só nos restará a contrição do orador romano: "Nos, nos consules, désumus!" Nós, nós professôres, falhamos. 
Desta Faculdade, estou certo, partirá a renovação almejada, tanto no plano do ensino quanto no das instituições políticas. Para essas missões foi ela talhada; de nenhuma outra poderão sair melhores lições. Nenhuma outra contará com maior autoridade para fazê-lo. Aqui já se levantaram bandeiras gloriosas e afinal triunfantes. Recordá-las seria retraçar a história desta escola, o que não caberia nos minutos de um discurso. Uma nova bandeira, agora, se levanta, a da Renovação.

Realmente, velha Faculdade, há uma nova campanha à tua frente. Reune teus soldados. Teu passado prenuncia o teu futuro. Ergue-te mais uma vez, marcha para outra batalha. Não fiques a descansar sôbre os louros. Levantate. Tuas tradições impõem-te a luta, auguram-te a vitória. Novas glórias te aguardam. Move-te, que São Paulo se haverá de mover contigo e com São Paulo todo o Brasil. Mostra que teu sangue ferve, como sempre, "pela lei, pela grei"! 